Adnan TINJIĆ

Arhiv Tuzlanskog kantona

E-mail: adnant@arhivtk.ba

Stručni rad/Professional article UDK/UDC:34:32(497.6)“1992“(047)

\title{
Izvještaj sa Međunarodne naučne konferencije "PRAVNE I POLITIČKE POSLJEDICE DEKLARACIJE O PROGLAŠENJU REPUBLIKE SRPSKOG NARODA BOSNE I HERCEGOVINE 9. JANUARA 1992. GODINE“, Gradska vijećnica u Sarajevu, Sarajevo, 8. i 9. januar 2020. godine
}

n Bošnjačka zajednica kulture

E "Preporod" i Udruženje Pokret "Majke enklave Srebrenica i Žepa“ organizirali su i uspješno realizirali međunarodnu naučnu konferenciju pod nazivom Pravne i političke posljedice Deklaracije o proglašenju Republike srpskog naroda Bosne i Hercegovine 9. januara 1992. godine. Navedena konferencija se održavala 8 . i 9.01.2020. godine, te je s pažnjom propraćena od naučne, ali i šire javnosti u Bosni i Hercegovini i okruženju.

U okviru navedene konferencije bila je postavljena i izložba JU Arhiva Tuzlanskog kantona pod nazivom "Srebrenica - genocid koji nije spriječen" autora Ešefe Begović i Izeta

MEDUNARODNA NAUČNA KONFERENCIJA

Pravne i političke posljedice Deklaracije o proglašenju Republike srpskog naroda Bosne i Hercegovine 9. januara 1992. godine

Gradska vijećnica u Sarajevu

8. i 9. januar 2020. godine

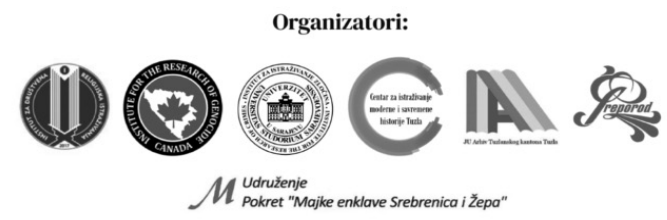
Šabotića, kao i izložba fotografija Ahmeta Bajrića Blicka na temu genocida u Srebrenici. 
Otvaranje Konferencije je upriličeno u srijedu, 8.01.2020. godine, u 11 sati u Gradskoj vijećnici u Sarajevu. Prilikom otvaranja prisutnima su se obratili: dr. sc. Šefko Sulejmanović, direktor Instituta za društvena i religijska istraživanja Tuzla, Nedžad Avdić, koji je govorio u ime žrtava genocida, Milan Dunović, potpredsjednik Federacije Bosne i Hercegovine, Ramiz Salkić, potpredsjednik bh entiteta Republika Srpska, Melika Mahmutbegović, potpredsjednica Federacije Bosne i Hercegovine, Dževad Hadžić, izaslanik Reis-ul-uleme i Šefik Džaferović, član Predsjedništva Bosne i Hercegovine.

Trideset $i$ šest eminentnih naučnika i istraživača iz osam zemalja: Bosne i Hercegovine, Hrvatske, Sjeverne Makedonije, Kanade, Norveške, Australije, Velike Britanije i SAD-a, prezentirali su vlastita istraživanja vezana za predmet konferencije u toku dva dana i četiri radne sesije.

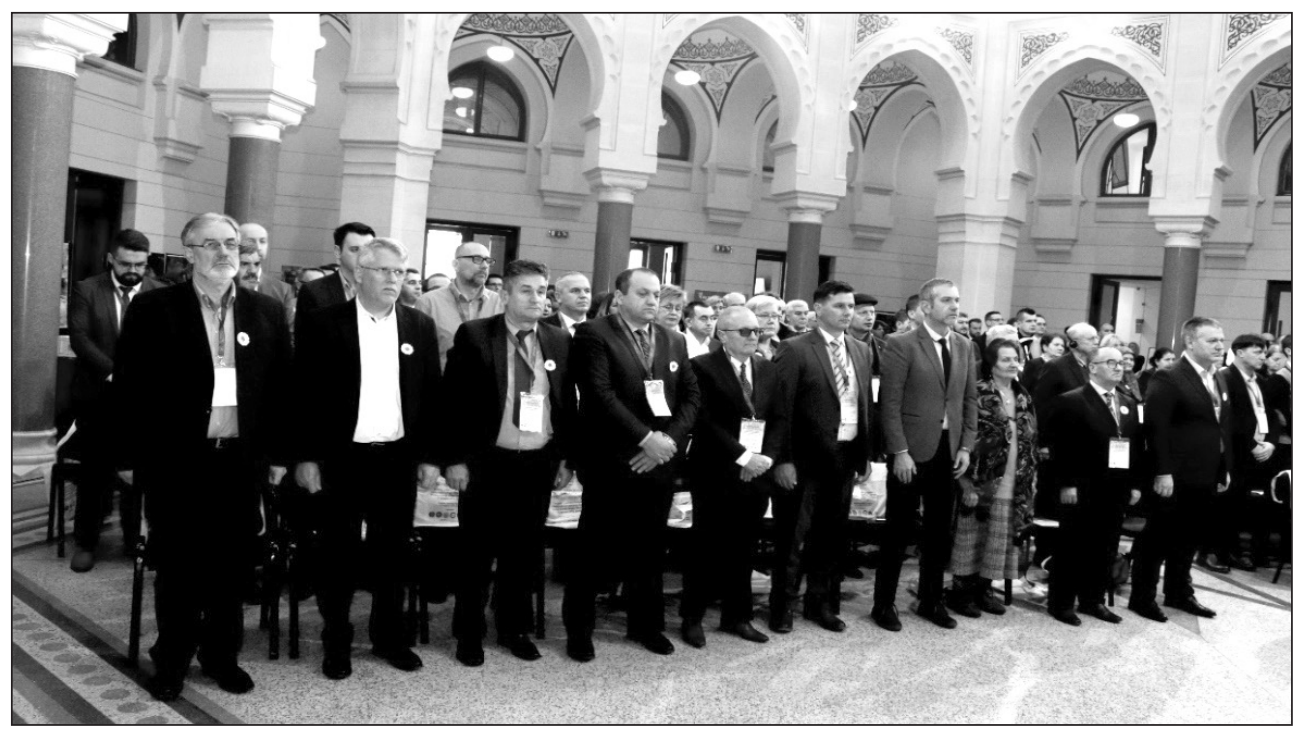

Prilog 2. Otvaranje Konferencije, hol Gradske vjećnice Sarajevo, 8. januar 2020. godine.

Prvog dana konferencije, 8.01.2020. godine u holu Gradske vjećnice u Sarajevu, u okviru Prve sesije, održane između 13:00 i 14:30, prisutnima su se predstavili slijedeći izlagači i teme:

1. David Pettigrew (SAD), Republika Srpska and the betrayal od the future;

2. John Hubbel Weiss (SAD), The Construction of the Public Memory of Genocides after Srebrenica: A Comparative Approach;

3. Adib Đozić (Bosna i Hercegovina), Paradigme zla ideologije srpskog velikodržavlja;

4. Hariz Halilović (Australija), Genocid kao politički i kulturni projekat Srbije i Republike Srpske;

5. Rusmir Šadić (Bosna i Hercegovina), Problem zla i filozofija hegemonije; 
6. Sandra Cvikić (Hrvatska), Dekonstrukcija međunarodno proizvedenih 'znanstvenih nepravdi' o bošnjačkim $i$ hrvatskim poslijeratnim traumatiziranim zajednicama;

7. Tomislav Pletenac (Hrvatska), Utemeljiteljsko nasilje kao posljedica juridičkog nesvjesnog;

8. Ann Petrila (SAD), The RS: Barriers to justice \& psychosocial healing in Bosnia \& Herzegovina.

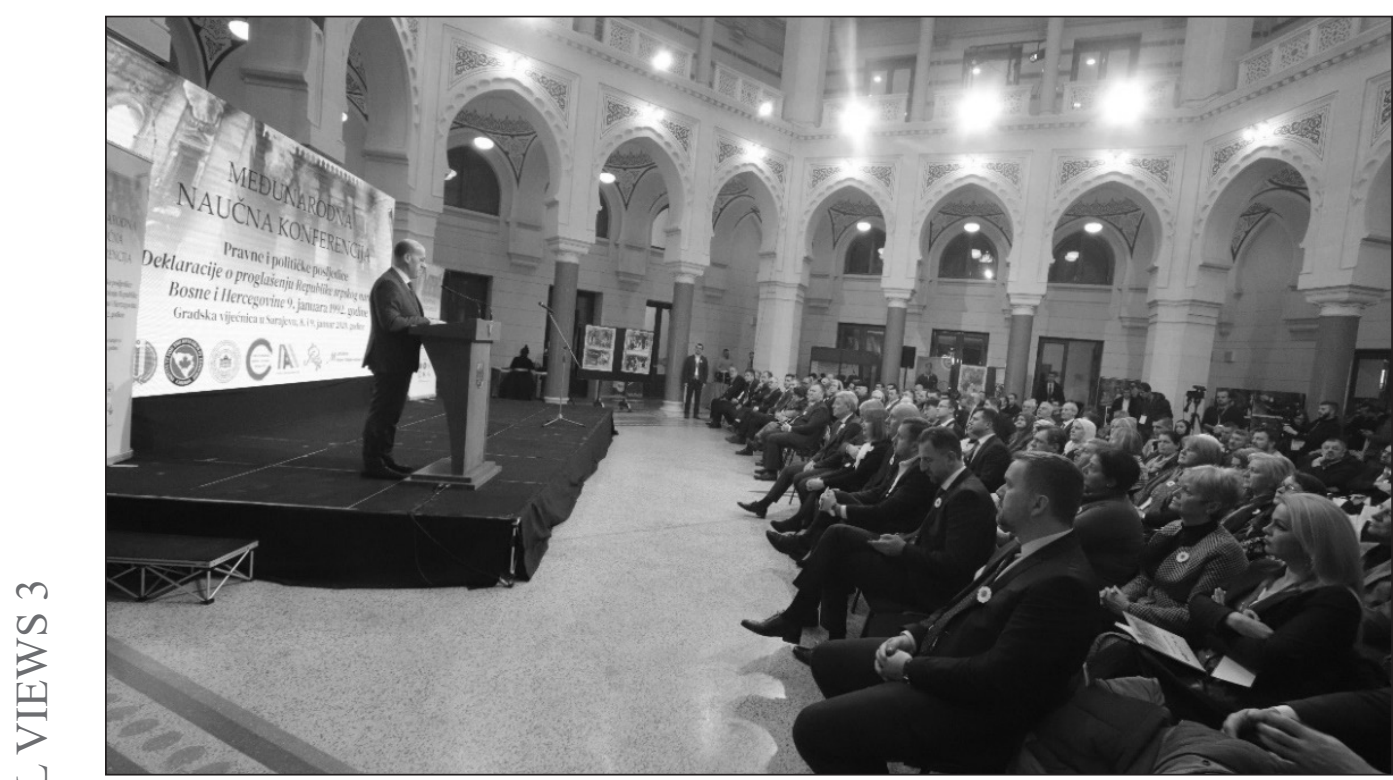

Prilog 3. Uvodna obraćanja na otvaranju Konferencije, 8. januar 2020. godina.

U okviru Druge sesije, koja je upriličena istog dana, u vremenskom periodu od 15:15 do 17:00 sati, prisutni su imali prilike poslušati naučne prezentacije slijedećih domaćih i međunarodnih izlagača:

1. Marko Attila Hoare (Velika Britanija), The place of the 9 january 1992. Proclamation of the Republic of the Serb people od Bosnia and Herzegovina in the aggresion against Bosnia and Hercegovina;

2. Dženeta Omerdić (Bosna i Hercegovina) Narodni suverenitet u Bosni $i$ Hercegovini;

3. Enis Omerović (Bosna i Hercegovina), Zahtjev za uništenje znatnoga $i$ značajnog dijela skupine: Novi element zločina genocida?

4. Vedad Gurda (Bosna i Hercegovina), Sporazumi o priznanju krivnje za ratne zločine u Bosni i Hercegovini: Između pokajanja i konsenzualne pravde;

5. Hikmet Karčić (Bosna i Hercegovina), Preludij zločinu: Institucionalni paralelizam i pripreme za uspostavljanje nove srpske države; 
6. Mujo Begić (Bosna i Hercegovina), Nasilni progon i prisilne deportacije Bošnjaka sa područja Bosanske krajine kao rezultat proglašenja Republike srpskog naroda u Bosni i Hercegovini;

7. Ajdin Huseinspahić i Sedad Dedić (Bosna i Hercegovina) Kontinuitet neustavnog $i$ protupravnog djelovanja na političkoj sceni $u$ Bosni $i$ Hercegovini od kraja XIX vijeka do danas - /Realnost ili imaginacija/;

8. Ahmed Lindov (Norveška), Pravni procesi kao uslov za trajni mir.

Drugog dana konferencije, 9. januara 2020. godine, u Sali Gradskog vijeća (Gradska vijećnica Sarajevo) također su održane dvije sesije. Treća sesija održana je između 10:00 do 11:30 časova, sa slijedećim temama:

1. Adnan Velagić (Bosna i Hercegovina), Bosanskohercegovački muslimani 1971. - kontroverze oko identiteta;

2. Emir Ramić (Kanada), 9. januar - početak užasa u Republici Bosni i Hercegovini i genocida nad Bošnjacima u srcu Evrope;

3. Izet Šabotić (Bosna i Hercegovina), Uništavanje kulturno - historijskog nasljeđa u vrijeme agresije na Bosnu i Hercegovinu 1992-1995. - osmišljen projekat velikodržavnih politika;

4. Šefko Sulejmanović (Bosna i Hercegovina), Devastacija i rušenje objekata islamske kulture na području općina Bijeljina i Brčko u periodu 1992-1995. godine;

5. Amir Kliko (Bosna i Hercegovina), Srpska i hrvatska nastojanja podjele Bosne i Hercegovine u cilju realizacije vlastitih velikodržavnih ideja u 20. stoljeću;

6. Meldijana Arnaut Haseljić (Bosna i Hercegovina), Opsada Sarajeva u kontekstu uspostavljanja Republike srpskog naroda Bosne i Hercegovine;

7. Muamer Džananović (Bosna i Hercegovina), Odnos „zapada“ prema zločinima u Bosni i Hercegovini u periodu 1992-1995;

8. Sead Selimović (Bosna i Hercegovina), Srebrenica nakon genocida nad Bošnjacima: Promjene u etničkoj i vjerskoj strukturi stanovništva.

Posljednja radna, četvrta, sesija uključivala je izlaganja, odnosno teme kako slijedi:

1. Sanjin Kodrić (Bosna i Hercegovina), Negiranje bosanstva i bošnjaštva $i$ ideološki aspekti obrazovnih, naučnih $i$ kulturnih politika $u$ bosanskohercegovačkom entitetu RS;

2. Alen Kalajdžija i Jasmin Hodžić (Bosna i Hercegovina), Društveno politički status službenih jezika u Bosni i Hercegovini;

3. Zećir Ramčilović (Sjeverna Makedonija), Bosna $i$ Hercegovina $u$ makedonskim pisanim medijima januara 1992. godine;

4. Mensur Husić i Midhat Čaušević (Bosna i Hercegovina), Diskriminacija $u$ srednjoškolskom obrazovanju u bosanskohercegovačkom entitetu Republika Srpska; 
5. Husejin Omerović (Bosna i Hercegovina), Formiranje Republike srpskog naroda Bosne i Hercegovine je bila uvertira u realizaciju velikosrpskog projekta;

6. Omer Zulić (Bosna i Hercegovina), Ratni zločini nad Bošnjacima sjeveroistočne Bosne u dokumentima Komisije za prikupljanje činjenica o ratnim zločinima;

7. Faruk Đozić (Bosna i Hercegovina), Zemljišnoknjižna reforma u Republici Srpskoj i njene posljedice;

8. Hasan Hasanović i Azir Osmanović (Bosna i Hercegovina), Memorijalni centar Srebrenica - Potočari: Mjesto sjećanja na genocid nad Bošnjacima „,zaštićene zone" UN Srebrenica.

Po okončanju izlaganja uslijedila je diskusija, kao i predstavljanje zaključaka konferencije. Po navedenim zaključcima, usvajanju Deklaracije o proglašenju Republike srpskog naroda Bosne i Hercegovine 9. januara 1992. godine prethodio je niz nezakonitih odluka tokom 1991. godine koje su donijeli ilegalni organi formirani od strane SDS uz pomoć vlasti iz Srbije. Posljedice Deklaracije su genocid nad Bošnjacima, sistemski progoni, ubistva, zatvaranja u logore, mučenja i drugi međunarodni zločini, koje su počinile jedinice tzv. vojske i policije RS uz kontrolu, pomoć i podršku tadašnje Savezne Republike Jugoslavije, kroz, na početku agresije, Jugoslavensku narodnu armiju, a kasnije jedinice Jugoslovenske vojske i paravojnih formacija iz ove države. Savjet sigurnosti Ujedinjenih nacija rezolucijom 752 od 15. maja 1992. godine napad na Republiku Bosnu i Hercegovinu proglasio je činom agresije.

Učesnici Konferencije pozvali su nadležne institucije u Bosni i Hercegovini da provedu presudu Ustavnog suda Bosne i Hercegovine kojom je 9. januar kao Dan Republike Srpske proglašen neustavnim, te su pozvali sve nivoe vlasti u Bosni i Hercegovini, a posebno nadležna tužilaštva, da otklone sve oblike diskriminacije građana, koji su utvrđeni presudama Evropskog suda za ljudska prava i domaćih sudova u Bosni i Hercegovini i osiguraju ravnopravnost građana i provođenje presuda na prostoru cijele Bosne i Hercegovine. Zauzet je i stav da Visoki predstavnik međunarodne zajednice za Bosnu i Hercegovinu treba da donese zakon o zabrani negiranja genocida na državnom nivou i time stane u zaštitu općih civilizacijskih vrijednosti. Pozivani su domaći i međunarodni faktori i države članice PIC-a involvirane u kreiranje i sklapanje Dejtonskog mirovnog sporazuma, uzimajući u obzir pravosnažne presude na međunarodnim sudovima i tribunalima, kao i nacionalnim sudovima država, da preispitaju funkcionalnost postojećeg uređenja Bosne i Hercegovine i otklone kočnice u njenom razvoju, te otklone diskriminirajući faktor iz naziva entiteta RS u skladu sa presudama Ustavnog suda Bosne i Hercegovine o konstitutivnosti naroda i uklanjanju prefiksa srpski iz naziva gradova u Bosni i Hercegovini. 
Također, učesnici konferencije podsjetili su da su međunarodni i nacionalni sudovi jednog broja država ostavili su obimnu arhivu dokaznog materijala korištenog u sudskim procesima. Uvidom u ovu građu i njenom naučnom analizom i interpretacijom u sljedećim godinama i decenijama, domaća i inozemna naučna zajednica nastavit će sa istraživanjem genocida nad Bošnjacima i demografskih, socijalnih, ekonomskih i političkih posljedica destrukcije u Bosni i Hercegovini. Buduća istraživanja će, utvrđivanjem činjenica, pomoći uklanjanju diskriminacije, uspostavljanju konstruktivnih društvenih odnosa u Bosni i Hercegovini, i uspostavi punog poštovanja prava i sloboda svih građana, te razvijanju dobrosusjedskih odnosa između Bosne i Hercegovine i zemalja u okruženju.

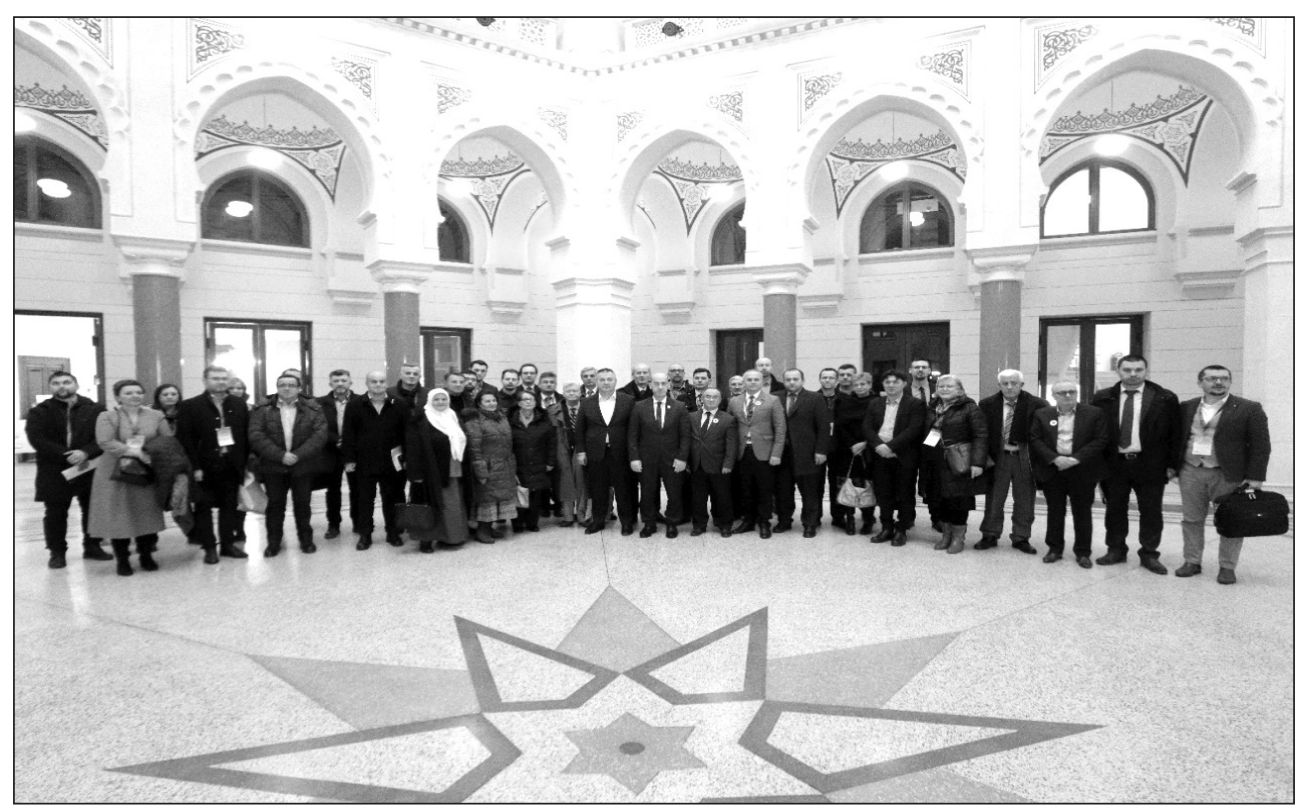

Prilog 4. Zajednička fotografija učesnika Konferencije, 9. januar 2020. godine.

Navedeno je i da ovi stavovi imaju za cilj uklanjanje diskriminacije i svih izvora diskriminacije, i nikako se ne mogu tumačiti na način da su usmjereni protiv srpskog ili bilo kojeg drugog naroda i njegovih prava.

O navedenim zaključcima diskutovano je, te je odlučeno da isti budu formirani u obliku jednog dopisa, koji će se uputiti odgovarajućim državnim organima i medijima, a u cilju kako bi rezultati i zapažanja naučnih djelatnika imali odjeka kako u javnosti, tako i među upravljačkim strukturama, koje su pozvane da djeluju u skladu sa navedenim zaključcima. 